\title{
Toward E-selective Olefin Metathesis: Computational Design and Experimental Realization of Ruthenium Thio-Indolate Catalysts
}

\author{
Immanuel Reim ${ }^{1}$ D $\cdot$ Giovanni Occhipinti $^{1}$ D $\cdot$ Karl W. Törnroos $^{1}$ (D) $\cdot$ Deryn E. Fogg $^{1,2}$ (D) Vidar R. Jensen ${ }^{1}$ (D)
}

Accepted: 29 June 2021 / Published online: 5 August 2021

(c) The Author(s) 2021

\begin{abstract}
The selective transformation of 1-alkenes into E-olefins is a long-standing challenge in olefin metathesis. Density functional theory (DFT) calculations predict high E-selectivity for catalysts incorporating a bidentate, dianionic thio-indolate ligand within a RuXX'(NHC)(py)(=CHR) platform $(\mathrm{NHC}=\mathrm{N}$-heterocyclic carbene; py = pyridine). Such complexes are predicted to yield E-olefins by favoring anti-disposed substituents in the transition state expected to be rate-determining: specifically, that for cycloreversion of the metallacyclobutane intermediate. Three pyridine-stabilized catalysts Ru21a-c were synthesized, in which the thio-indolate ligand bears a $\mathrm{H}, \mathrm{Me}$, or $\mathrm{Ph}$ substituent at the $\mathrm{C} 2$ position, and the NHC ligand is the unsaturated imidazoline-2-ylidene $\mathrm{Me}_{2} \mathrm{IMes}$ (which bears $\mathrm{N}$-mesityl groups and methyl groups on the $\mathrm{C} 4,5$ backbone). Single-crystal $\mathrm{X}$-ray diffraction analysis of Ru21c confirms the ligand orientation required for E-selective metathesis, with the thio-indolate sulfur atom binding cis to the NHC, and the indolate nitrogen atom trans to the NHC. However, whereas the new complexes mediated metathetic exchange of their 2-thienylmethylidene ligand in the presence of the common metathesis substrates styrene and allylbenzene, no corresponding self-metathesis products were obtained. Only small amounts of 2-butene (73\% (Z)-2-butene) were obtained in self-metathesis of propene using Ru21a. Detailed DFT analysis of this process revealed that product release is surprisingly slow, limiting the reaction rate and explaining the low metathesis activity. With the barrier to dissociation of (Z)-2-butene being lower than that of (E)-2-butene, the calculations also account for the observed Z-selectivity of Ru21a. These findings provide guidelines for catalyst redesign in pursuit of the ambitious goal of E-selective 1-alkene metathesis.
\end{abstract}

\section{Graphic abstract}

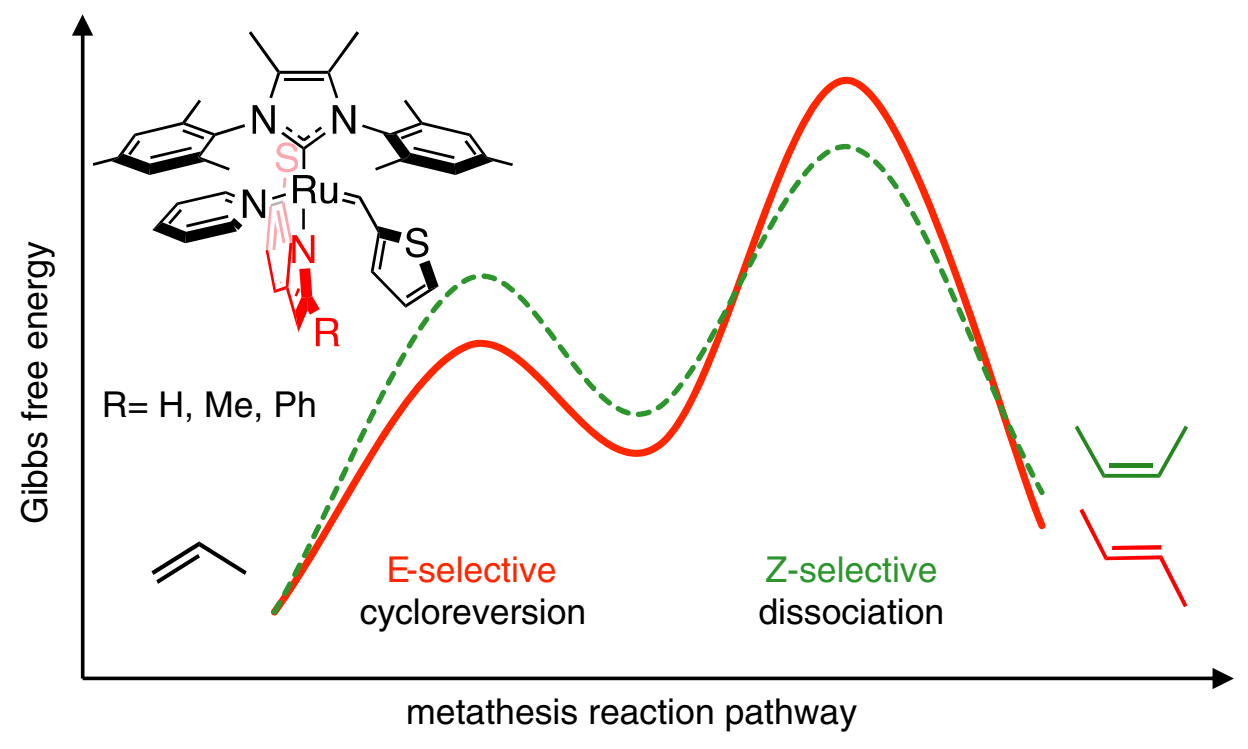

Extended author information available on the last page of the article 
Keywords Olefin metathesis $\cdot$ Ruthenium $\cdot$ Alkylidene $\cdot$ Stereoselectivity $\cdot$ Density functional theory $\cdot$ Reaction mechanism

\section{Introduction}

E-olefins, with substituents trans-disposed across the double bond, are important structural features in molecular entities ranging from antibiotics [1] and anticancer therapeutics $[2,3]$ to precision polymers [4]. Traditionally, such compounds have been generated from aldehydes via stoichiometric approaches such as the Wittig [5], Horner-WadsworthEmmons [6] and Julia [7] olefination reactions. Interest in catalytic methodologies is spurred by the low atom-efficiency of these classic methods (most notoriously, the Wittig reaction, with its stoichiometric formation of triphenylphosphine oxide as coproduct). Olefin metathesis offers an atomefficient catalytic alternative, in which olefinic fragments are rearranged by scission and regeneration of carbon-carbon double bonds [8-10]. Thanks to the ease of handling and functional-group tolerance of ruthenium catalysts [11-13], olefin metathesis has been widely adopted for the synthesis of complex organic molecules [14-17], including pharmaceuticals [18-21], and soft materials [22-31].

A plethora of ruthenium olefin metathesis catalysts has been developed since the 1990s [32-34]. Whereas many of these catalysts have been optimized for specific reactions and purposes, they typically generate E-Z (cis-trans) product mixtures. Separating the target product from its undesired isomer is costly, wasteful, and sometimes impossible. The most direct, atom-economic, and elegant solution is offered by catalysts that enable selective synthesis of the singleisomer target [33, 35-37]. However, design of such catalysts is challenging. Kinetically $Z$-selective catalysts for 1 -alkene metathesis have been achieved only in the last decade, and only two such classes of catalyst exist: cyclometalated (Chart 1a, Ru1-8) [38-44], and monothiolate catalysts (Chart 1a, Ru9-12) [45-51].

Even more elusive are catalysts for E-selective olefin metathesis. Despite more than 20 years of effort, no catalyst for E-selective metathesis of 1-alkenes has yet been achieved. To date, metathetical access to E-olefin products can be achieved only via "stereoretentive" catalysts (Chart 1b), which can transform stereochemically defined E-olefin substrates into E-configured products (Scheme 1) $[36,52-55]$. The utility of stereoretentive metathesis is limited by the cost and accessibility of the isomerically pure starting materials required. Production of E-olefinic products from 1-alkenes represents an intellectually and economically attractive alternative.

Here we describe work toward the design of catalysts for E-selective 1-alkene metathesis. Building on insights obtained in earlier modifications of stereoretentive catalysts

[56], we explore a new family of thio-indolate catalysts for which E-selectivity is predicted on the basis of density functional theory (DFT) calculations.

\section{Results and Discussion}

\subsection{Initial Considerations}

Stereoselective metathesis is achieved by controlling the catalyst stereochemistry in of the rate-determining step of the Chauvin mechanism [57], typically cycloreversion to release

a

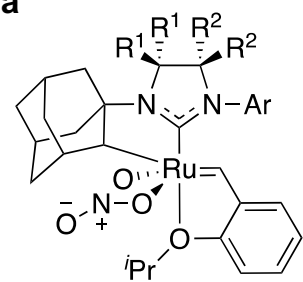

Ru1: $\mathrm{Ar}=$ Mes, $\mathrm{R}^{1}=\mathrm{R}^{2}=\mathrm{H}$

Ru2: $\mathrm{Ar}=\mathrm{Dipp}, \mathrm{R}^{1}=\mathrm{R}^{2}=\mathrm{H}$

Ru3: $\mathrm{Ar}=\mathrm{Mes}, \mathrm{R}^{1}=\mathrm{Me}, \mathrm{R}^{2}=\mathrm{H}$

Ru4: $\mathrm{Ar}=\mathrm{Mes}, \mathrm{R}^{1}=\mathrm{H}, \mathrm{R}^{2}=\mathrm{Me}$

Ru5: $\mathrm{Ar}=\mathrm{Dipp}, \mathrm{R}^{1}=\mathrm{H}, \mathrm{R}^{2}=\mathrm{Me}$

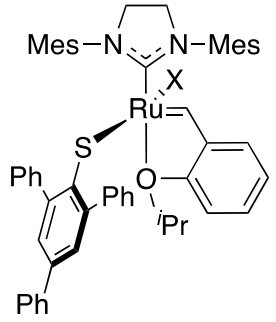

Ru9: $\mathrm{X}=\mathrm{Cl}$

Ru10: $X=$ NCO

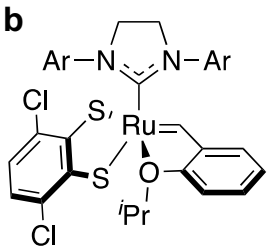

Ru13: $\mathrm{Ar}=$ Mes

Ru14: $\mathrm{Ar}=\operatorname{Dipp}$

Ru15: Ar = 2-flouro-6-methylphenyl

Mes $=2,4,6$-trimethylphenyl

Dipp $=2,6$-diisopropylpheny

py $=$ pyridine

Chart 1 Examples of (a) Z-Selective Ru Catalysts and (b) Stereoretentive Ru Catalysts

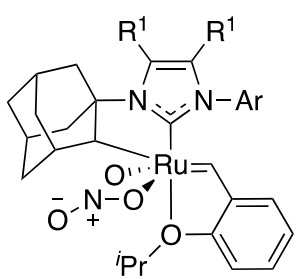

Ru6: $\mathrm{Ar}=\mathrm{Mes}, \mathrm{R}_{1}=\mathrm{Me}$

Ru7: $\mathrm{Ar}=$ Dipp, $\mathrm{R}_{1}=\mathrm{Me}$

Ru8: $\mathrm{Ar}=\mathrm{Dipp}, \mathrm{R}_{1}=\mathrm{H}$

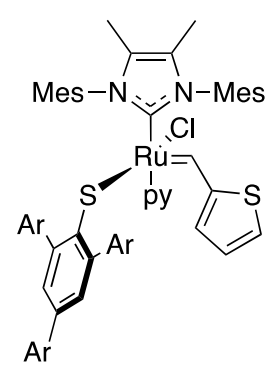

Ru11: $\mathrm{Ar}=$ phenyl

Ru12: $\mathrm{Ar}=3,5$-dimethylphenyl

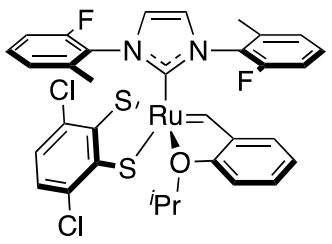

Ru16 

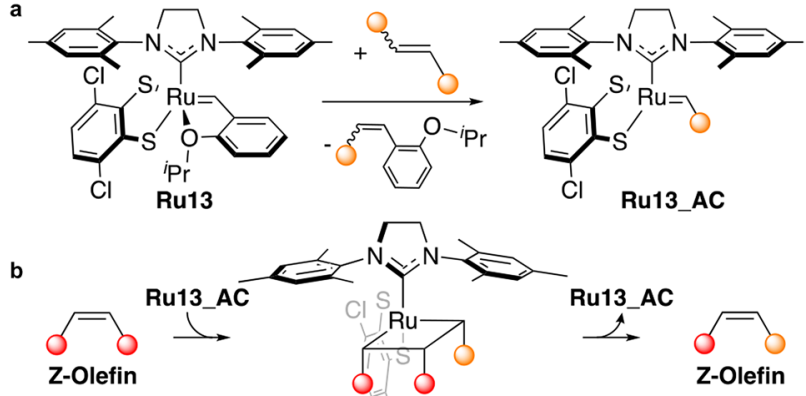

Ru13_MCB-Z

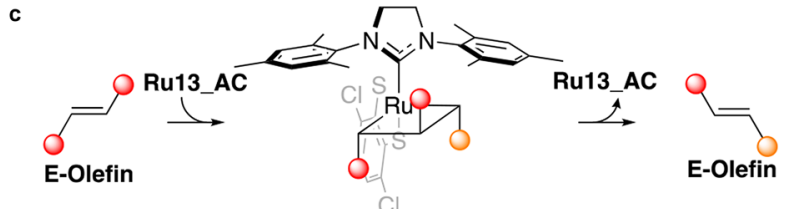

Scheme 1 Mechanism for Stereoretentive Metathesis, Illustrated with Thiocatecholate Catalyst Ru13. a Precatalyst Initiation, Stereoretentive Metathesis for $\mathbf{b}$ Z-olefin and $\mathbf{c}$ E-olefin

the product olefin from the metallacyclobutane (MCB) intermediate [53, 58-60]. A syn relationship between the substituents in the MCB results in a Z-configured product; antidisposed MCB substituents yield an E-configured product.

Seminal computational mechanistic work showed that the MCB intermediates and the associated transition states of the preferred dissociative reaction pathways adopt trigonal bipyramidal (TBP) geometries, in which the $\eta^{2}-\mathrm{C}_{\alpha}-\mathrm{C}_{\beta}-\mathrm{C}_{\alpha}$ ring occupies the equatorial plane [61]. Such a geometry is likewise observed for stereoretentive catalysts Ru13-16 (Scheme 1b) [36, 53-55, 62-64]. In the MCB intermediate, the NHC ligand occupies one of the two axial sites: that is, it is cis to the MCB ring. This positions the NHC N-aryl substituents in close proximity to the MCB $\alpha$-carbon atoms. Steric pressure from the N-Ar groups hence forces orientation of the $\mathrm{C}_{\alpha}$-substituents away from the NHC.

If stereochemically-defined internal olefins are used as substrates, this also sets the orientation of the $\beta$-substituent. The substrate stereochemistry thus controls the stereochemistry of the metathesis product. That is, use of an E-olefin dictates formation of an E-configured product; a Z-olefin substrate yields a Z-configured product (Scheme 1) [60]. These stereoretentive catalysts offer the only current metathetical route to E-olefins. They are therefore an attractive starting point for the next logical step: developing catalysts that selectively convert 1-alkenes to E-configured alkene products, and circumventing the need for isomerically pure starting materials.

Discussed above is the means by which steric pressure on the $\alpha$-substituent of the MCB enables formation of Z- (Scheme 1b) or E-configured products (Scheme 1c) via retention of the substrate stereochemistry. E-selective metathesis of 1-alkenes, in contrast, requires steric pressure on the $\beta$-substituent. Grubbs and co-workers pursued this objective by introducing a phenanthrene-dithiolate ligand (Fig. 1) [56]. In the key MCB intermediate, however, the favored isomer is the undesired Ru17_22, in which the phenanthrene ring system is oriented away from the MCB $\beta$-position. Moreover, even for the target isomer Ru17_22', DFT calculations on a model, unsubstituted MCB predicted a $5 \AA$ separation between $\mathrm{H}_{\beta}$ and the phenanthrene ring. Larger substituents would reduce this distance, but the catecholthiolate ligand appears too distant to influence the orientation of the $\beta$-substituent to any great extent. This prompted us to pursue design of alternative dianionic ligands with greater influence on the $\beta$-site of the MCB, using DFT calculations as a guide.

\subsection{Computational Ligand Design}

To reduce the distance between the selectivity-inducing group and the MCB $\beta$-position, we envisaged replacing one $\mathrm{S}$-donor with a trivalent, anionic donor, thereby retaining a neutral Ru complex. Specifically, we considered introduction of a nitrogen center bearing a substituent that would reduce the distance to the MCB ring. We further stipulated a planar, rigid, and bicyclic $\kappa^{2}-S, N$ ligand, to maximize steric pressure on the MCB $\beta$-position.

These requirements led us to the thio-indolate scaffold shown in the model unsubstituted MCB (Ru19a_22) in Chart 2. The DFT-optimized geometry of Ru19a_22 revealed a much shorter distance between $\mathrm{H}_{\beta}$ and the indole ring than between $\mathrm{H}_{\beta}$ and the thiocatecholate ring in Ru13_22 (2.35 Å vs $5.95 \AA$, respectively: Chart 2). Substitution at position 2 of the indolate ring should reduce the distance further, increasing the steric pressure. Using propene as a computationally efficient model 1 -alkene, we investigated the impact of different substituents at the indole 2-position using DFT calculations.

Thio-indolate catalyst Ru19a, with only a hydrogen atom at position 2 of the indole ring, is predicted to be E-selective, as judged from the difference in free energy between the transition states leading to (Z)- or (E)-2-butene $\left(\Delta \Delta \mathrm{G}_{(\mathrm{E} / \mathrm{Z})}^{*}=\right.$ $\Delta \mathrm{G}_{\mathrm{Z}}^{\ddagger}-\Delta \mathrm{G}_{\mathrm{E}}^{\ddagger}=3.4 \mathrm{kcal} \mathrm{mol}^{-1}$ : see Table 1$)$. In contrast, the state-of-the-art catecholthiolate catalyst Ru13 [53] (Chart 1) is predicted to be Z-selective $\left(\Delta \Delta \mathrm{G}_{(\mathrm{E} / \mathrm{Z})}^{\ddagger}=-1.2 \mathrm{kcal} \mathrm{mol}^{-1}\right)$, in agreement with experiment: using Ru13, 83\% Z-selectivity is obtained in self-metathesis of propene. ${ }^{1}$ Also of note, lower barriers to metathesis are predicted for thio-indolate

\footnotetext{
1 NMR experiment: A J. Young NMR tube was loaded with $5 \mathrm{mg}$ (10 mmol) Ru13 and $0.5 \mathrm{mg}(3.3 \mathrm{mmol})$ hexamethylbenzene as internal standard in $0.65 \mathrm{~mL} \mathrm{C}_{6} \mathrm{D}_{6}$. The solution was degassed via 3 freeze-pump-thaw cycles, thawed under propene and mixed, at which point the timer was started. The selectivity was determined
} 
Fig. 1 Phenanthrene-dithiolate complex Ru17 and its TBP-like MCB intermediates [56]. The steric bulk of the extended dithiolate ligand is located far from the critical $\beta$-position in the favored isomer Ru17_22

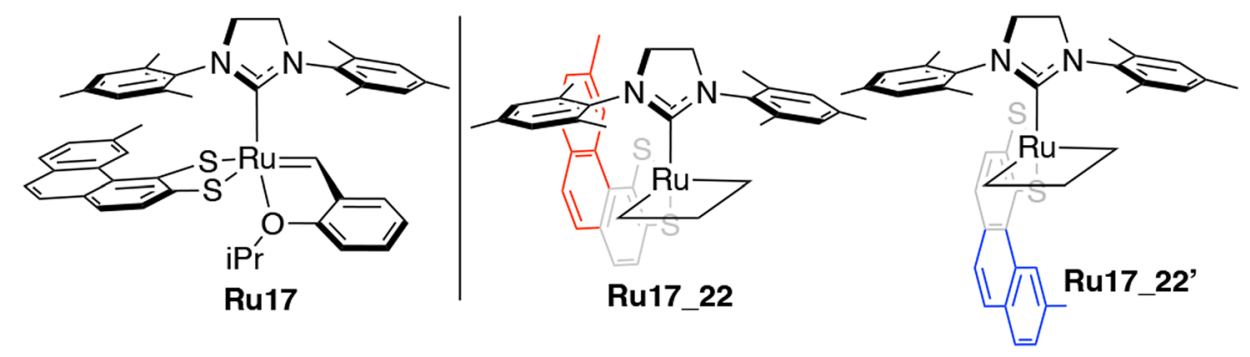

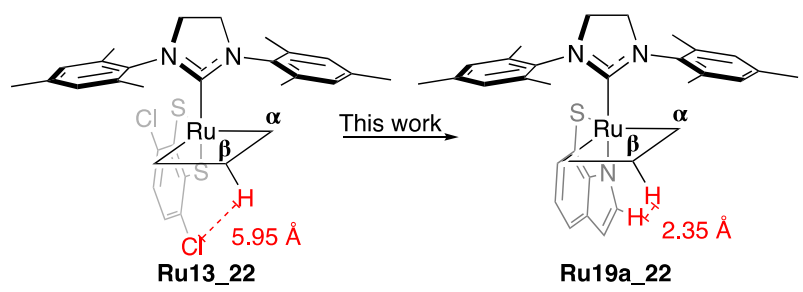

Chart 2 Thiocatecholate vs Thio-indolate Ligands: Amplifying Steric Pressure at the MCB $\beta$-Position. DFT-calculated interatomic distances

catalysts Ru19a and Ru19b (the latter bearing a 2-Me substituent) vs $\operatorname{Ru} 13\left(\Delta \mathrm{G}_{\mathrm{Z}}^{\ddagger}=21.0 \mathrm{kcal} \mathrm{mol}^{-1}\right)$ as well vs a corresponding (hypothetical) catalyst precursor Ru18 bearing the same methoxybenzylidene as Ru19a-c. These data reinforce the potential of the thio-indolate ruthenium alkylidenes as olefin metathesis catalysts.

2-Substitution destabilizes the Z-transition state more than the corresponding E-isomer, leading to increasing E-selectivity with increasing substituent size (Table 1). With a methyl substituent, for example (Ru19b), $\Delta \Delta \mathrm{G}_{(\mathrm{E} / \mathrm{Z})}^{\ddagger}$ is $0.6 \mathrm{kcal} \mathrm{mol}^{-1}$ higher than that of Ru19a. A phenyl substituent (Ru19c) is predicted to increase the selectivity substantially $\left(\Delta \Delta \mathrm{G}_{(\mathrm{E} / \mathrm{Z})}^{\ddagger}=11.5 \mathrm{kcal} \mathrm{mol}^{-1}\right)$, but the significantly higher barrier to metathesis is expected to limit the catalytic activity of Ru19c relative to Ru19a and Ru19b.

The increased selectivity predicted for Ru19a is a result of the steric pressure on the MCB $\beta$-substituent, as discussed above. This pressure is reflected in the increased $\mathrm{Ru}-\mathrm{C}_{\beta}-\mathrm{CH}_{3}$ angle $\left(119^{\circ}\right.$ in $\mathbf{R u 1 3} \_\mathbf{T S 4}, \mathbf{5}_{\mathbf{Z}}$, vs $126^{\circ}$ in $\mathbf{R u 1 9 a} \mathbf{T S S}_{\mathbf{2}} \mathbf{5}_{\mathbf{Z}}$ : Fig. 2), and the decreased $\mathrm{C}_{\mathrm{NHC}}-\mathrm{Ru}-\mathrm{C}_{\beta}$ angle (which declines from $105^{\circ}$ to $92^{\circ}$ ).

\section{Footnote 1 (continued)}

from the ratio of (Z)- and (E)-2-butene (86:14) in the first ${ }^{1} \mathrm{H}$ NMR spectrum $(\mathrm{t}=5 \mathrm{~min})$, to reduce the effect of isomerization (see Table S1).
Table 1 Predicted barriers to propene self-metathesis, and computed $E-Z$ selectivity for catalysts Ru18 and Ru19a-c ${ }^{a}$

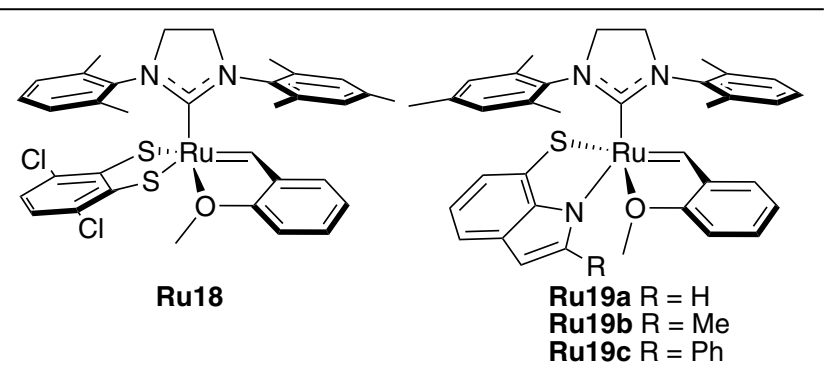

\begin{tabular}{llllc} 
Cat & $\mathrm{R}$ & $\Delta \mathrm{G}_{\mathrm{E}}^{\ddagger}$ & $\Delta \mathrm{G}_{\mathrm{Z}}^{\ddagger}$ & $\Delta \Delta \mathrm{G}_{\mathrm{E} / \mathrm{Z}^{b}}^{\ddagger}$ \\
\hline Ru19a & $\mathrm{H}$ & 17.9 & 21.3 & 3.4 \\
Ru19b & $\mathrm{Me}$ & 19.0 & 23.2 & 4.0 \\
Ru19c & $\mathrm{Ph}$ & 24.1 & 35.5 & 11.5 \\
Ru18 & - & 22.7 & 21.5 & -1.2 \\
Ru13 $^{\mathrm{c}}$ & - & 22.2 & 21.0 & -1.2 \\
\hline
\end{tabular}

${ }^{\mathrm{a}}$ Energies $\left(\mathrm{kcal} \mathrm{mol}^{-1}\right)$ calculated relative to the Gibbs free energy of the $[\mathrm{Ru}]=$ CHAr precursor. ${ }^{b}$ Free energy difference $\Delta \Delta \mathrm{G}_{\mathrm{E} / \mathrm{Z}}^{\ddagger}=\Delta \mathrm{G}^{\ddagger} \mathrm{Z}$ $-\Delta \mathrm{G}^{\ddagger} \mathrm{E} \cdot{ }^{\mathrm{c}}$ See Chart 1 for the structure of Ru13

\subsection{Experimental Realization}

In light of the promising effect of the thio-indolate ligands on metathesis stereoselectivity, we proceeded to synthesize the first versions of ruthenium alkylidenes bearing such ligands. The required 7-bromoindoles L1a-c (Scheme 2) are commercially available.

A thiol group was installed in place of the bromine atom by Pd-catalyzed exchange with a silylthiolester [65], following which the thiol was deprotected with $\mathrm{HCl}(\mathrm{R}=\mathrm{Me}$, $\mathrm{Ph})$ or $\mathrm{N}^{\mathrm{n}} \mathrm{Bu}_{4} \mathrm{~F}(\mathrm{R}=\mathrm{H})$. This two-step protocol delivered the corresponding thio-indoles L3a-c in yields of $68-72 \%$. Ensuing treatment with KH in THF afforded the dianions as potassium salts (L4a-c), which were extracted with hexane to remove $\mathrm{PPh}_{3}$ residues introduced in the prior steps.

Salt metathesis of L4a-c with the second-generation Hoveyda catalyst HII to give Ru19a-c failed, despite the success of the corresponding reactions with unsubstituted [53, 
Fig. 2 Optimized geometries of the Z-isomeric transition states for cycloreversion in propene self-metathesis by complexes Ru13 and Ru19a. Ruthenium is shown in violet, sulfur in yellow, nitrogen in blue, chlorine in green, and carbon in gray. Distances in $[\AA]$, angles in $\left[{ }^{\circ}\right]$

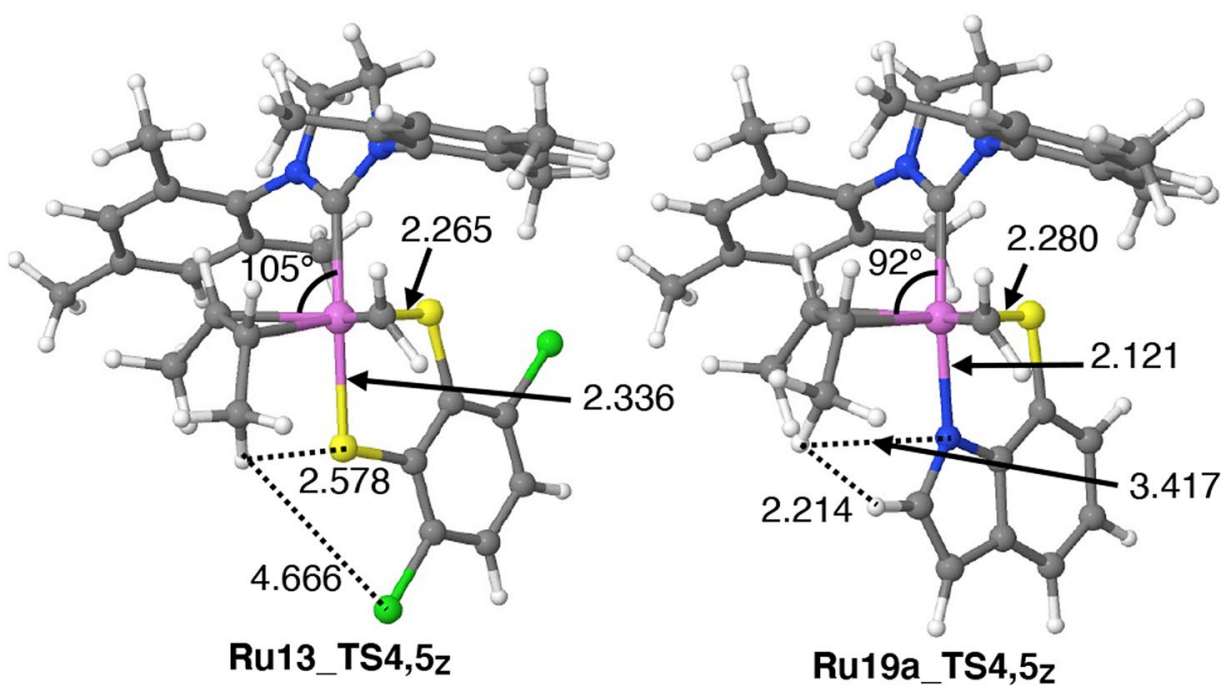

62] or sterically demanding [56] catecholthiolates. Reaction of L4c with the third-generation Grubbs catalyst GIII proceeded, but the formed complex was unstable and could not be purified. Greater success was achieved in salt metathesis with the Evonik catalyst Ru20, perhaps because of the reduced steric demand of the 2-thienylmethylidene and the unsaturated NHC ligand. It may be noted that Ru20 has been successfully used as a precursor to other Z-selective catalysts bearing sterically demanding thiolates [49]. The target thio-indolate alkylidene complexes Ru21a-c $(\mathbf{a}: \mathrm{R}=\mathrm{H}$; $\mathbf{b}$ : $\mathrm{R}=2-\mathrm{Me} ; \mathbf{c}: \mathrm{R}=2-\mathrm{Ph} ;$ Scheme 2) were obtained in $60-65 \%$ yield. These are, to our knowledge, the first transition-metal complexes bearing thio-indolate chelate ligands. The new complexes were characterized by NMR and MS analysis, and, in the case of Ru21a and Ru21c, single-crystal X-ray diffraction (Fig. 3). The X-ray crystal structure of Ru21a confirms that the atom connectivity is analogous to that of Ru21c, but the diffraction quality is too low for detailed structural analysis.

The X-ray structure confirms binding of the thio-indolate fragment as a S,N-chelate. Crucially, and as predicted by the DFT calculations, the dianionic ligand adopts the orientation required for E-selective metathesis, with the thiolate sulfur cis, and the indolate nitrogen trans, to the NHC (Table S6). However, DFT calculations predict that the unintended isomer (Ru21a'), with the thiolate sulfur trans and the indolate nitrogen cis to the NHC, is only $1.9 \mathrm{kcal} \mathrm{mol}^{-1}$ less stable and may thus also be present (see Table S7). Indeed, ${ }^{1} \mathrm{H}$ NMR spectra of catalyst Ru21a consistently exhibit a minor alkylidene singlet (5\%) at $\delta=15.4 \mathrm{ppm}$, with the main alkylidene signal located at $\delta=16.2$. A NOESY experiment confirms the existence of an exchange equilibrium between these two alkylidene singlets, with the minor alkylidene species being $1.8 \mathrm{kcal} \mathrm{mol}^{-1}$ less stable than the dominating species. From the agreement between the NMR experiments and the DFT calculations, the minor species is presumed to be Ru21a'. Such minor alkylidene species are not observed for the larger complexes Ru21b-c, and calculations also indicate that the isomers Ru21b' and Ru21c' with rotated S,N ligands are high in energy (Table S6).

Despite Ru21c having a slightly more acute $\mathrm{N} 1-\mathrm{Ru}-\mathrm{S}$ chelate bite angle than the corresponding $\mathrm{S}-\mathrm{Ru}-\mathrm{S}$ angle in $\operatorname{Ru13}\left(\left(85.11(4)^{\circ}\right.\right.$ vs $88.23(3)^{\circ}$, respectively) [53], its N-Ru$\mathrm{C}_{\mathrm{NHC}}$ is considerably greater $\left(162.78(6)^{\circ}\right.$, vs $148.03(11)^{\circ}$ in Ru13). This presumably reflects the weaker trans influence of nitrogen relative to sulfur. The mutual trans disposition of the NHC and indolate nitrogen in Ru21c weakens the $\mathrm{Ru}-\mathrm{N} 1$ indolate bond (2.1301(5) $\AA$ ), which is longer than known Ru-pyrrole bonds (2.065 - 2.115 $\AA$ ) [66-68].

The metathesis activity of Ru21a-b was initially assessed by reaction with styrene at room temperature (Scheme 3). Unexpectedly, ${ }^{1} \mathrm{H}$ NMR analysis showed no evidence of the stilbene self-metathesis product. However, a new alkylidene singlet was observed, along with vinylthiophene, in the experiments involving Ru21a and Ru21b ( $\delta 17.2$ and $16.9 \mathrm{ppm}$, respectively, in $\mathrm{C}_{6} \mathrm{D}_{6}$ : Fig. S2, S3). The new alkylidene species, identified as the benzylidene analogues of Ru21a and Ru21b (labeled Ru21a_29 and Ru21b_29, respectively) result from unproductive metathesis of styrene, via Ru21a_28 (see Scheme 3, Fig. S2-S4, and Scheme S1). ${ }^{2}$ Complex Ru21a reaches equilibrium within $15 \mathrm{~min}$, vs nearly an hour for catalyst Ru21b. The slower reaction of Ru21b is consistent with the higher barrier to metathesis

\footnotetext{
2 The NMR experiment showed that the consumption of styrene and starting complex Ru21a or Ru21b corresponds to the formation of the new alkylidenes, respectively, as well as of 2-vinylthiophene. Therefore, the new alkylidenes were assigned to benzylidene complexes Ru21a_29 and Ru21b_29 (see SI).
} 
Scheme 2 Ligand synthesis and installation

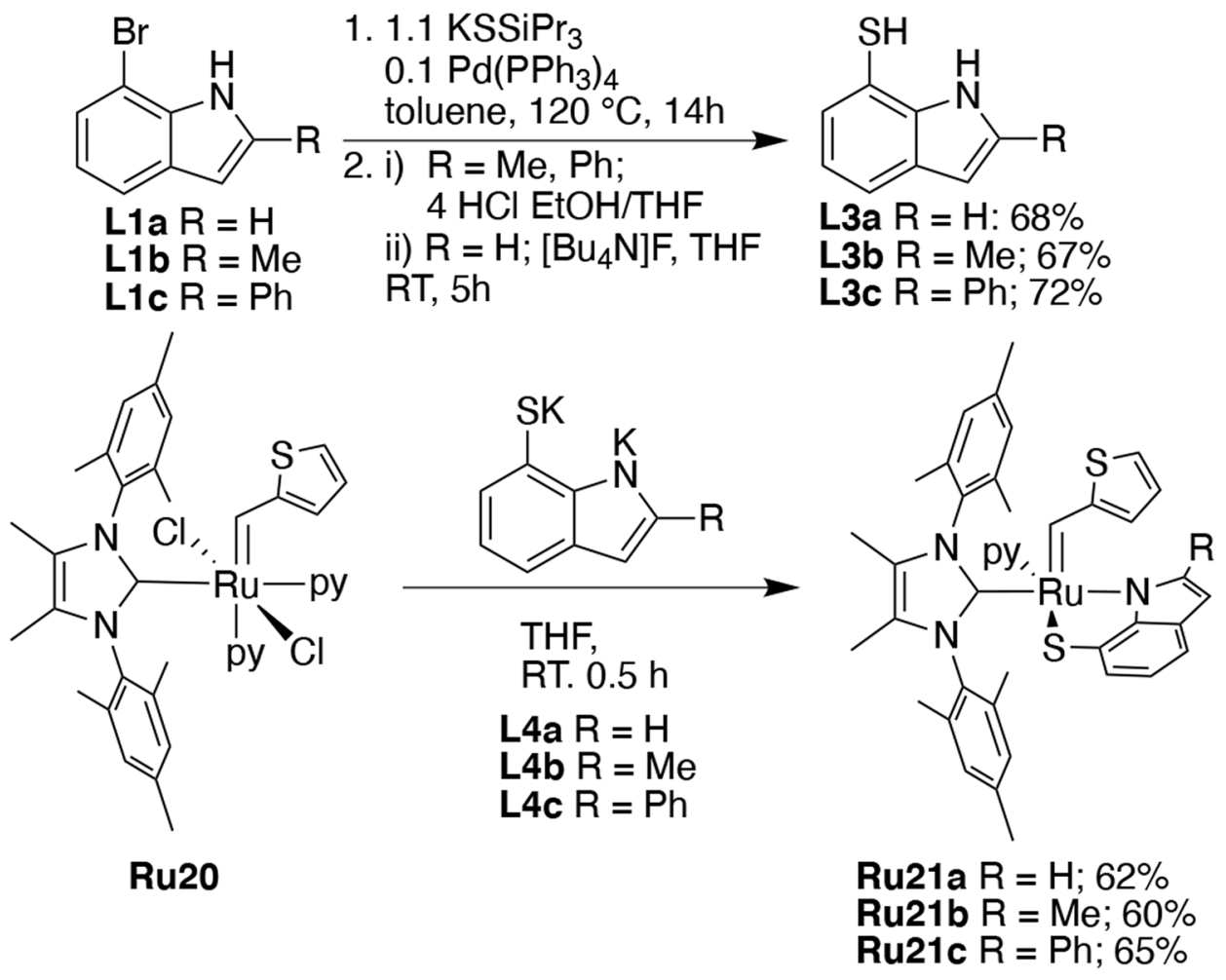

calculated for the bulkier thio-indolate ligands of the $\mathrm{H}_{2} \mathrm{IMes}$ analogues Ru19 (Table 1). Increasing the reaction temperature or time resulted in loss of the alkylidene signals as well as a black precipitate indicating catalyst decomposition and formation of $\mathrm{Ru}$ nanoparticles [69].

In light of the low reactivity documented above, especially for $\mathbf{R u 2 1 b}$, we speculated that unfavorable steric interactions may hamper productive metathesis. Formation of stilbene would necessitate an MCB structure in which the $\beta$-phenyl substituent approaches the two N-mesityl groups (for the (E)-stilbene), or the thio-indolate ligand (for the (Z)-stilbene). The impact on the barriers to metathesis is explored computationally below.

To test whether reduced steric bulk at $\mathrm{C}_{\beta}$ would enable productive metathesis, we examined the reaction with allylbenzene (Fig. S5). Again, however, no metathesis products were detected. In the case of $\mathbf{R u 2 1 b}, 35 \%$ vinylthiophene was detected by ${ }^{1} \mathrm{H}$ NMR analysis (Fig. S5, S6), but $17 \%$ Ru21b remained even after $12 \mathrm{~h}$, confirming slow initiation and a relatively stable precatalyst. Isomerization of allylbenzene was also observed, presumably catalyzed by decomposed Ru species [69, 70]. In sum, attempts at selfmetathesis of allylbenzene led to catalyst decomposition and substrate isomerization, rather than productive metathesis.

Next, to reduce the steric pressure as much as possible, with the goal of facilitating productive metathesis, we attempted self-metathesis of propene in NMR experiments with Ru21a-c. ${ }^{3}$ Ru21a gave the expected butene product in low yield (11 mol\% vs catalyst loading), and the proportion of the Z-isomer was slightly lower than that obtained with catalyst Ru13 (73\% vs 83\%). The more sterically demanding catalysts Ru21b-c afforded no butene product. For catalyst Ru21b, this is clearly due in part to low metathesis activity, as unreacted Ru21b remained even after $96 \mathrm{~h}$ at $50{ }^{\circ} \mathrm{C}$. In contrast, the alkylidene signal of catalyst Ru21c disappeared within $12 \mathrm{~h}$ of reaction time.

The small amount of butene obtained using Ru21a in propene self-metathesis may be due to either low catalytic activity, perhaps caused by the steric hindrance of the thioindolate ligand, or to catalyst decomposition. To probe its susceptibility to $\beta$-hydride elimination from the unsubstituted MCB (a key decomposition pathway in 1-alkene metathesis for a range of Ru-NHC catalysts [71]), Ru21a

\footnotetext{
${ }^{3{ }^{1} \mathrm{H}-\mathrm{NMR}-E x p e r i m e n t}$ A J. Young NMR tube was loaded with 10 mmol catalyst Ru21a-c and $0.5 \mathrm{mg}(3.3 \mathrm{mmol})$ hexamethylbenzene as internal standard in $0.65 \mathrm{~mL} \mathrm{C}_{6} \mathrm{D}_{6}$. The solution was degassed via three freeze-pump-thaw cycles and then charged with propene gas, mixed and the timer was started. For Ru21b and Ru21c no 2-butene formation was observed even after $24 \mathrm{~h}$ and heating the reaction mixture to $50{ }^{\circ} \mathrm{C}$. For Ru21a, the selectivity was determined as the ratio of the formed ( $\mathrm{Z}$ )- and (E)-2-butene (73:27) of the a quatintative $1 \mathrm{H}$ NMR spectrum $(\mathrm{t}=60 \mathrm{~min})$ to reduce the effect of isomerisation and higher accuracy (see Table S1).
} 


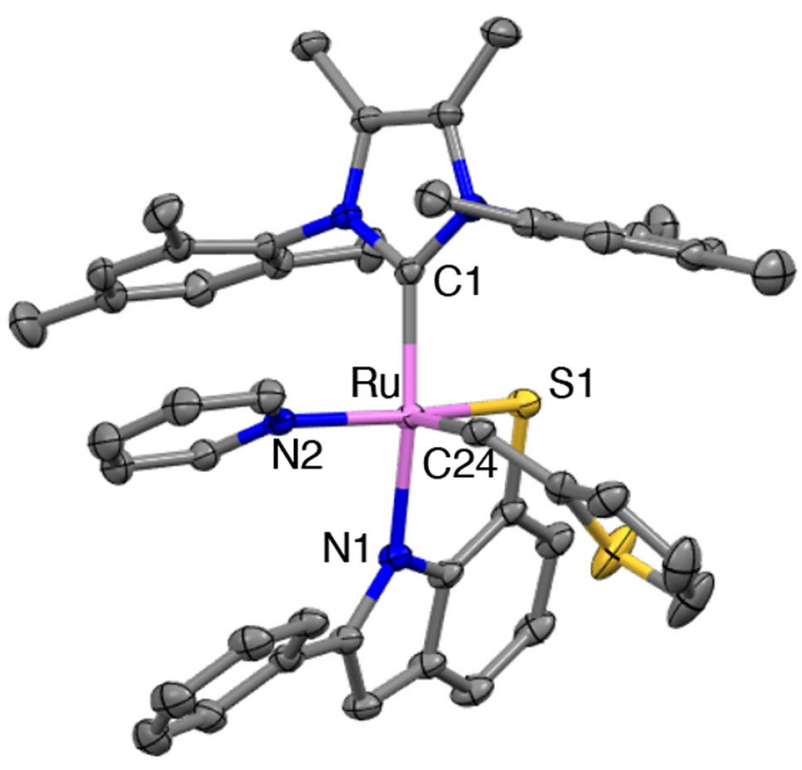

Fig. 3 X-ray crystal structure of Ru21c, with displacement ellipsoids drawn at $50 \%$ probability. Ruthenium is shown in violet, sulfur in yellow, nitrogen in blue, and carbon in gray. Hydrogen atoms have been omitted for clarity. Key bond metrics: Ru-C1: 2.0704(17) A. Ru-N1:

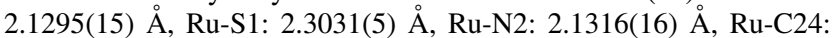
1.8490(18) $\AA$; N1-Ru-S1: 85.11(4) ${ }^{\circ}$, S1-Ru-C1: 87.27(5) ${ }^{\circ}$, N1-RuC1: $162.78(6)^{\circ}$

was reacted with ethylene. Both vinylthiophene and propene ${ }^{4}$ were detected, evidence for alkylidene exchange (catalyst initiation), and $\beta$-hydride elimination (Fig. S7, S8). The proportion of propene is consistent with decomposition of ca. $40 \%$ of the catalyst via $\beta$-hydride elimination. (Bimolecular decomposition of the 4-coordinate methylidene species may also occur [72], but the ethylene product is indistinguishable from ethylene formed via metathesis). The competition between metathesis and decomposition is further explored in the mechanistic computational analysis below.

\subsection{Mechanistic Calculations}

The calculated barrier to cycloreversion - the presumed rate-determining step - for Ru19a (the $\mathrm{H}_{2}$ IMes analogue of Ru21a) is similar to that of the known metathesis catalyst Ru13 [53, 58-60]. Nevertheless, Ru21a is inactive in metathesis of styrene or allylbenzene, and produced only small proportions of 2-butene in self-metathesis of propene. Moreover, the major stereoisomer produced was (Z)-2-butene, despite the predicted E-selectivity of Ru19a (Table 1).

\footnotetext{
${ }^{4}$ Indolate-induced deprotonation of the MCB [71] was ruled out as a source of propene, since calculations with stepwise reduced $\mathrm{N}-\mathrm{H}_{\mathrm{C} \beta}$ distance invariably led, instead, to $\beta$-hydride elimination. Also, upon completion of the reaction, no $\mathrm{NH}$ signals were observed in the ${ }^{1} \mathrm{H}-$

${ }^{15}$ N-HSQC-NMR spectrum.
}

To uncover the factors underlying the discrepancy between the catalytic properties predicted for Ru19a and those observed for Ru21a, the latter was subjected to detailed computational analysis.

The calculated barrier to cycloreversion in self-metathesis of styrene and allylbenzene to E-configured products by Ru21a is 36.9 and $37.5 \mathrm{kcal} \mathrm{mol}^{-1}$ (Scheme S12, Table S7), respectively, consistent with the absence of product ${ }^{5}$ observed experimentally. In contrast, for propene, the cycloreversion barrier (via Ru21a_TS4,5, $23.8 \mathrm{kcal} \mathrm{mol}^{-1}$ vs the precursor Ru21a) leading to formation of (E)-2-butene, is only $2.8 \mathrm{kcal} \mathrm{mol}^{-1}$ higher than that of the state-of-the-art catecholthiolate catalyst Ru13 (Table 1), indicating that the critical bond rupture and formation of propene metathesis should be within reach for Ru21a. The catalytic potential of Ru21a seems even clearer when eliminating the effect of the precursor (the pyridine-coordinated Ru21a vs the isopropoxybenzylidene-coordinated Ru13), by calculating free energies relative to the two active ethylidene complexes derived from Ru21a (Ru21a_2) and Ru13 (Ru13_2), respectively (Scheme 4). In fact, with initiation completed, Ru21a_2 should mediate both cycloaddition and cycloreversion faster than Ru13_2. However, Ru21a is observed to be less active in metathesis than Ru13. Because Ru21a is unlikely to be limited by slow initiation (initiation was observed even for styrene and allylbenzene; see above), the most likely explanation for its slow metathesis lies in a reaction step other than cycloreversion.

In searching for an alternative rate-limiting step, we did not initially consider 2-butene dissociation. However, Cavallo and co-workers, in an early computational study of the stereoselectivity of propene self-metathesis using a $\mathrm{RuCl}_{2}\left(\mathrm{H}_{2} \mathrm{IMes}\right)$-ethylidene catalyst [73], found the methylidene complex and 2-butene to be of higher energy than any other minimum or transition state in the catalytic cycle. Even if this is not the case for Ru21a, the relatively high energies of complexes toward the end of the pathway indicate that product release could be slow. For example, the 2-butene $\pi$-complexes Ru21a_5 are significantly less stable than the propene counterparts Ru21a_3. We therefore considered whether product release from Ru21a_5 might be rate determining. Indeed, product release is surprisingly costly (10-13 kcal mol ${ }^{-1}$ vs Ru21a_5, see Scheme 4, or 29-32 $\mathrm{kcal} \mathrm{mol}^{-1}$ vs Ru21a), and is the undisputed bottleneck for the thio-indolate catalyst. This step, which is difficult to follow computationally, ${ }^{6}$ was not investigated for the corresponding thio-catecholate catalyst Ru13. However,

\footnotetext{
5 Transition-state theory suggests that reactions with free-energy barriers approaching $30 \mathrm{kcal} \mathrm{mol}^{-1}$ will be impractically slow. See the SI for details.

6 The flat potential energy surfaces in the transition regions at long $\mathrm{Ru}$-butene distances make these transition states hard to find.
} 
Scheme 3 Metathesis of Styrene

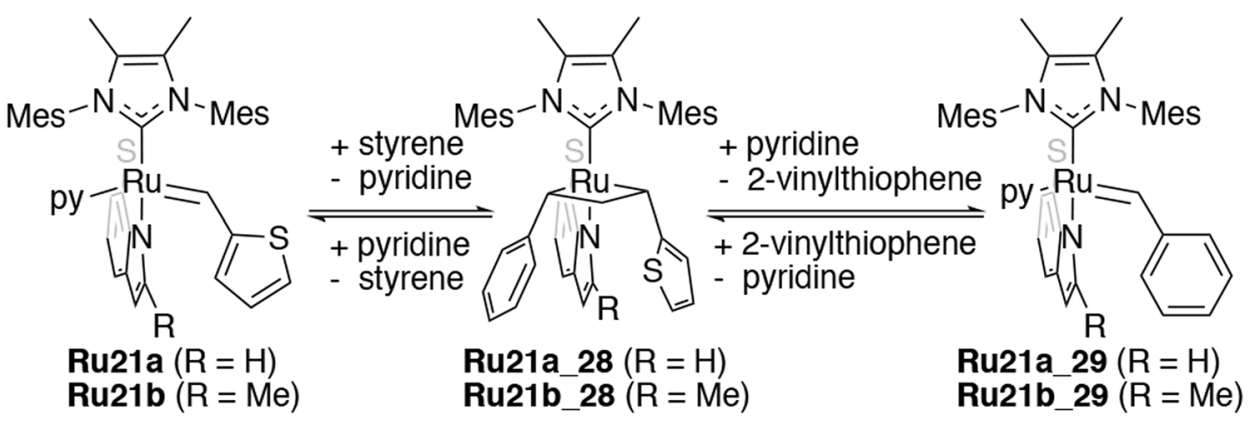

product release is not expected to be a bottleneck for the latter, which is less bulky than Ru21a. Previous computational studies of this catalyst do not suggest rate-limiting product dissociation [53, 55, 60]. Instead, cycloreversion has been suggested to be rate limiting for this and other stereoretentive catalysts [60].

In summary, with cycloreversion assumed to be rate determining for Ru13 and product release being identified as the bottleneck for Ru21a, the calculations are consistent with the much lower catalytic activity of Ru21a relative to the closely related thio-catecholate catalyst Ru13. The calculations are also consistent with the observed Z-selectivity of both Ru21a and Ru13, given the lower barrier to dissociation of (Z)-2-butene than (E)-2-butene from Ru21a_5, and the lower barrier to cycloreversion via Ru13_TS4,5 than Ru13_TS4,5 .

The calculations indicate that product release is a twostep process. Surprisingly high barriers for the thio-indolate catalyst are located in the first step, involving rearrangement from $\eta^{2}$ - to $\eta^{1}$-coordinated 2-butene (Fig. 4). This rearrangement requires considerable activation, as the $\mathrm{Ru}$-butene $\pi$-bond is lost at the same time as the steric repulsion between the ligands (the NHC and the thio-indolate) and the leaving, but still largely $\eta^{2}$-coordinated, 2-butene, is large. The steric repulsion is lower for (Z)-2-butene than for (E)-2-butene, resulting in lower barriers to rearrangement to the agostic complex. The reduced steric hindrance results, at least in part, from (Z)-2-butene being more compact than its

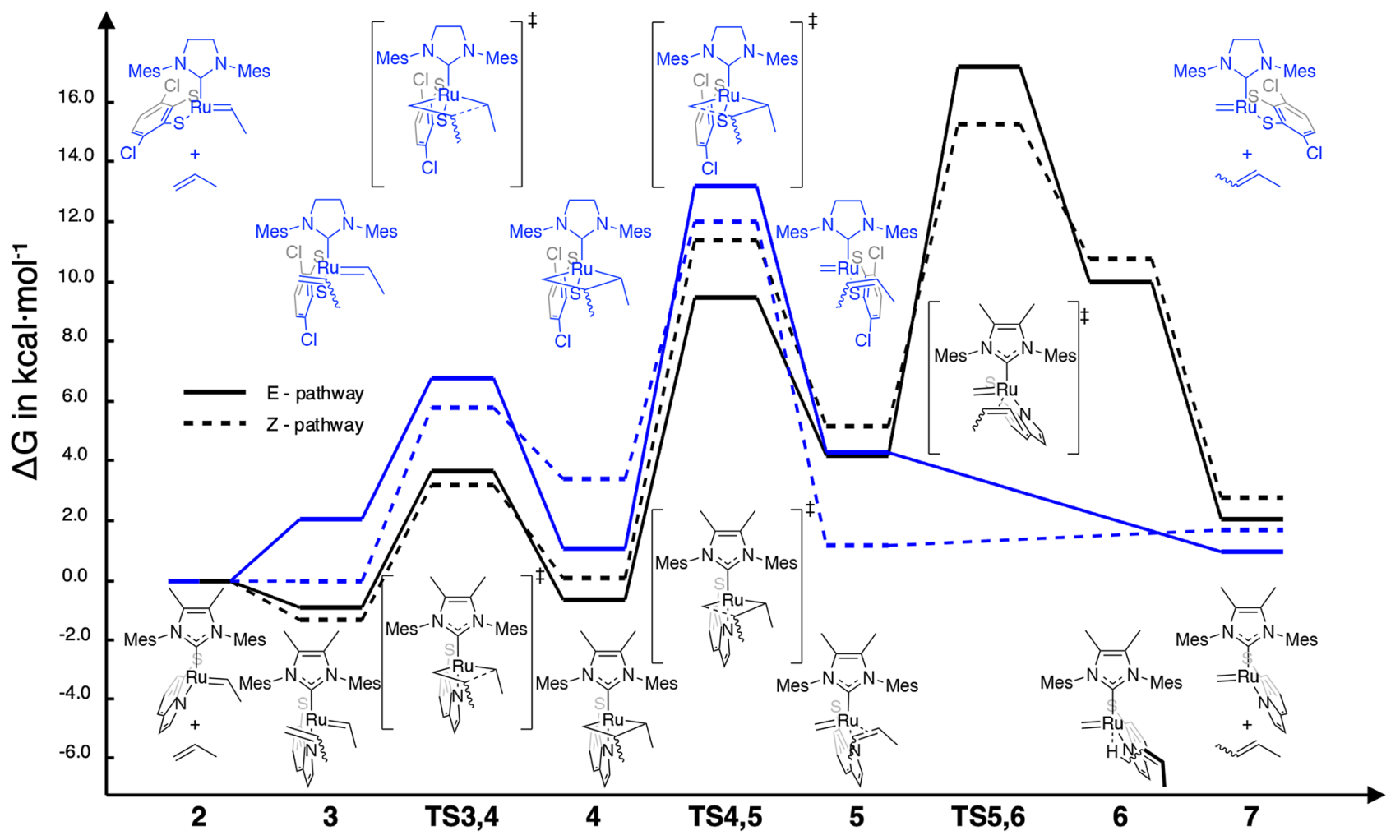

Scheme 4 Calculated Free Energies of Propene Metathesis vs Ru21a_2 (black) and Ru13_2 (blue) 
Fig. 4 The optimized transition states for rearrangement of $\eta^{2}$-bound to $\eta^{1}$-bound 2-butene in $\pi$-complexes Ru21a_5E and Ru21a_5Z to give the corresponding agostic complexes Ru21a_6E and Ru21a_6Z, respectively. This rearrangement is the rate-determining step of Ru21a-mediated propene metathesis and initiates product release. The subsequent (E)or (Z)-2-butene dissociation to give methylidene complex Ru21a_7 requires less geometric adaption and less activation. Distances in $[\AA]$, angles in $\left[^{\circ}\right]$. Molecular volumes (V) and surface areas (A) are those of the solute cavity in the continuum solvent-model calculations (see SI)
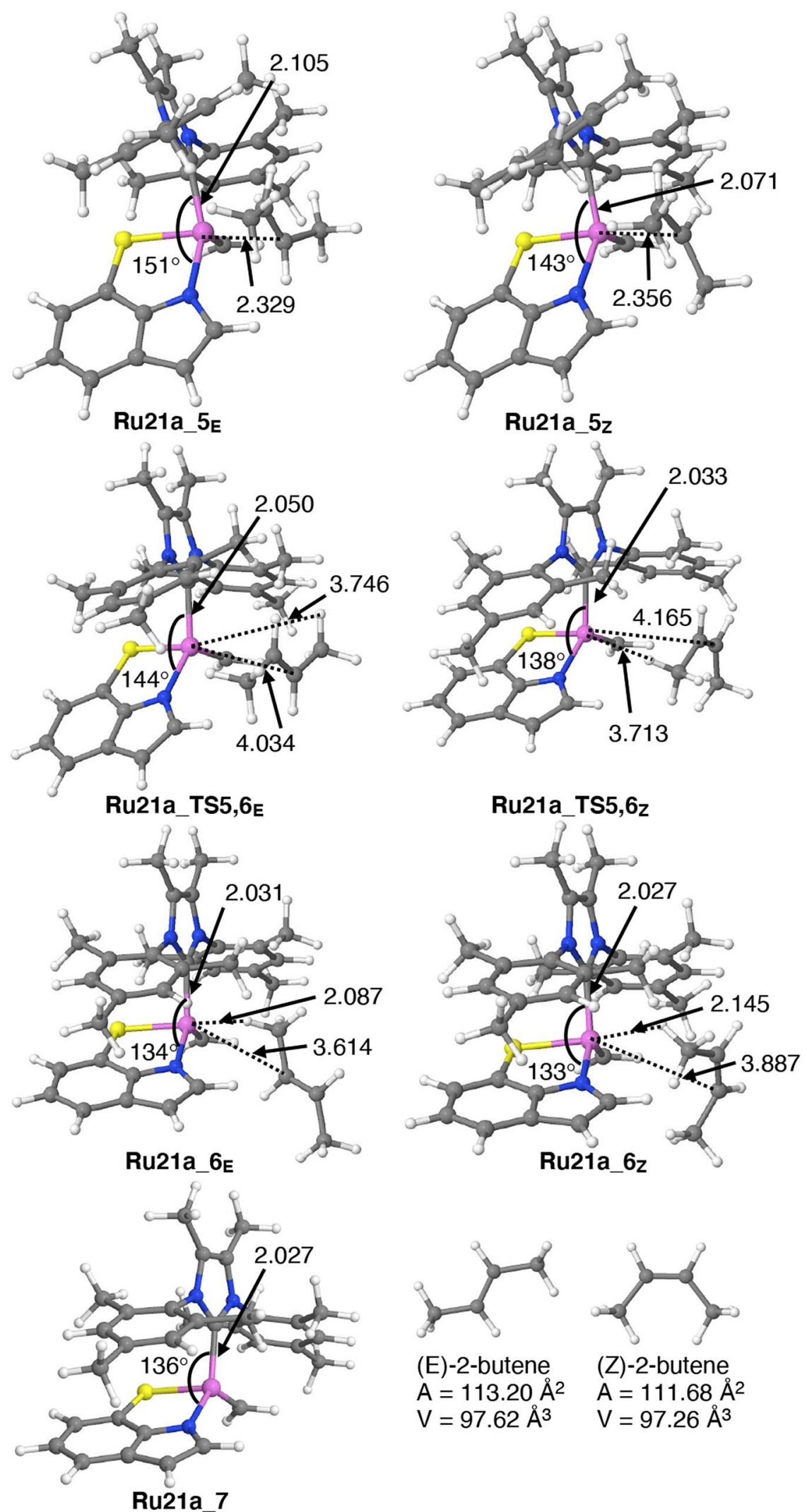

(E)-2-butene

$A=113.20 \AA^{2}$

$V=97.62 \AA^{3}$

(Z)-2-butene

$A=111.68 \AA^{2}$

$V=97.26 \AA^{3}$ 
E-counterpart, with a smaller molecular volume and surface area, (Fig. 4). Faster release of the Z-configured product is likely to be a challenge extending far beyond the current thio-indolate catalyst design: regardless which of the existing catalyst frameworks is chosen as a starting point for design of E-selective catalysts, substitution is likely to be essential to disfavor formation of Z-configured products. This substitution will increase the overall steric pressure and tend to make product release the kinetic bottleneck.

The slowest step of the product release, the $\eta^{2}$-to- $\eta^{1}$ bound 2-butene rearrangement, leads to sterically less encumbered complexes Ru21a_6, in which 2-butene is bound to $\mathrm{Ru}$ via an agostic methyl $\mathrm{C}-\mathrm{H}$ bond. From Ru21a_6, the continued 2-butene dissociation to methylidene Ru21a_7 and free 2-butene requires much less geometric adaption (see Fig. 4) and is thus expected to require little activation. Constrained geometry optimizations at increasing $\mathrm{R}-\mathrm{H}_{\text {agostic }}$ distances and failed attempts at locating the corresponding transition states ${ }^{6}$ confirm that this, the final part of the product release, requires only negligible enthalpic activation from Ru21a_6.

To shed further light on the factors underlying the low observed metathesis activity, we also investigated a range of decomposition modes for Ru21a and its isomer Ru21a'. Specifically, we considered $\beta$-H elimination [74] and nucleophilic attack of the thio-indolate ligand on the alkylidene [53] during productive (Scheme S5), non-productive (Scheme S6) and regenerative propene metathesis (i.e., regeneration of the ethylidene Ru21a_2: Scheme S7). In addition, nucleophilic attack and $\beta$-hydride elimination, occurring during reaction of the Ru-methylidene with ethylene, were examined (Scheme S8).

Consistent with the observed formation of propene on reaction of Ru21a with ethylene (see above), the calculations indicate a relatively low barrier to $\beta$ - $\mathrm{H}$ elimination of the unsubstituted MCB $\left(\Delta \mathrm{G}^{\ddagger}=21.7 \mathrm{kcal} \mathrm{mol}^{-1}\right.$ vs Ru21a). However, the barrier to $\beta$-hydride elimination is consistently higher (by 4.5-6.2 $\mathrm{kcal} \mathrm{mol}^{-1}$ ) than that of cycloreversion during metathesis itself (Scheme S5-S8). Thus, thio-indolate catalyst Ru21a does not appear to be particularly vulnerable to $\beta$-H elimination.

The calculations suggest that nucleophilic attack is more likely (Scheme S5-S8). Indeed, consistent with the previously reported nucleophilic attacks of both catechothiolates [53] and amines [75, 76] on alkylidenes, indolate attack on the ethylidene during regenerative metathesis emerges as the dominant decomposition pathway $\left(\Delta \mathrm{G}^{\ddagger}=19.7 \mathrm{kcal} \mathrm{mol}^{-1} \mathrm{vs}\right.$ Ru21a, Scheme S7). This reaction releases ethylene, which, in turn, may react with a second ruthenium ethylidene or methylidene complex, thereby accelerating decomposition. However, the calculations do not suggest that this vulnerability to nucleophilic attack is inherent to the design of Ru21a, with the indolate nitrogen atom trans to the NHC.
In fact, the thiolate moiety of the unintended isomer Ru21a' more readily attacks the ethylidene $\left(\Delta \mathrm{G}^{\ddagger}=17.8 \mathrm{kcal} \mathrm{mol}^{-1}\right.$ vs Ru21a, Scheme S7) than does the indolate of Ru21a. In fact, the corresponding barrier to thiolate attack for the well-known dithiolate catalyst Ru13 is even lower $\left(\left(\Delta \mathrm{G}^{\ddagger}=12.6 \mathrm{kcal} \mathrm{mol}^{-1}\right.\right.$ vs Ru13, Scheme S3).

In short, the calculations reveal no decomposition modes intrinsic to the thio-indolate catalyst design that should make these catalysts more vulnerable than, e.g., the related dithiolate catalyst Ru13. Instead, the low catalytic activity and the decomposition observed for these catalysts appear to be the result of unusually high barriers to releasing the internal-olefin product at the end of the metathesis reaction. The exceptional height of these barriers originates from the added steric pressure of the thio-indolate ligand required to achieve E-selectivity.

\section{Conclusion}

Based on considerations of the geometries of stereoretentive metathesis catalysts [77] and on catecholthiolate modifications aimed at increasing the share of E-isomeric product [56], a thio-indolate ligand scaffold was designed to exert steric pressure on the $\beta$-substituent of the MCB, and the MCB-like transition states for cycloaddition and cycloreversion. DFT calculations predicted that the $\mathrm{S}, \mathrm{N}$-thio-indolate chelate should bind to ruthenium with an orientation suitable to exert the desired steric pressure. Furthermore, DFT-calculated energy differences $\left(\Delta \Delta \mathrm{G}_{(\mathrm{E} / \mathrm{Z})}^{\ddagger}\right.$ between the cycloreversion transition states for propene self-metathesis leading to (Z)-2-butene and (E)-2-butene suggested that ruthenium-alkylidene thio-indolate complexes would favor E-isomer products.

To follow up the computational predictions, the first metal complexes bearing bidentate thio-indolate ligands were synthesized, isolated, and characterized (Ru21a-c). The thio-indolate chelates are compatible with the 2-thienylmethylidene and $\mathrm{Me}_{2} \mathrm{IMes}$ ligands present in known, active metathesis catalysts, and the general robustness of complexes Ru21a-c is comparable to that of other ruthenium catalysts for olefin metathesis.

However, whereas the new complexes participated in metathetic exchange with styrene and allylbenzene, liberating the 2-thienylmethylidene ligand, no self-metathesis products were obtained. Even self-metathesis of propene using Ru21a yielded only small proportions of 2-butene (73\% (Z)).

Detailed mechanistic DFT calculations of propene selfmetathesis by Ru21a and its isomer Ru21a' revealed barriers to product release from the $\mathrm{Ru}-2$-butene $\pi$-complex much higher than those of cycloreversion of the MCB, the step repeatedly identified as rate limiting in computational studies 
of ruthenium-catalyzed olefin metathesis [53, 58-60]. The barriers to product release are also much higher than those of common decomposition reactions, and are caused by the additional steric bulk of the thio-indolate. This steric bulk leaves little room for the escaping, bulky disubstituted olefin, which experiences steric repulsion from the thio-indolate ligand, in particular, and the mesityl methyl groups of the $\mathrm{Me}_{2} \mathrm{IMes}$ ligand. This repulsion adds to the cost of losing the Ru-olefin $\pi$-bond, resulting in unusually high barriers to product release. The negative effect of steric bulk predicted by the calculations is consistent with the metathesis inactivity of the bulkier complexes Ru21b and Ru21c.

E-selective 1-alkene metathesis catalysts have been sought in vain for more than two decades. The present study reveals the dual challenge of this molecular-design goal: (1) Steric pressure must be exerted in opposite directions to closelyspaced substituents of the nascent disubstituted olefin. (2) The net steric congestion must be sufficiently low to permit productive metathesis and, in particular, for the product olefin to dissociate from the metal. The thio-indolate complexes described herein are, to our knowledge, the first catalysts for which calculations suggest that Challenge 1 can be met. However, these findings also underline the difficulty in achieving E-selectivity without incurring excessive steric congestion.

Supplementary Information The online version contains supplementary material available at https://doi.org/10.1007/s11244-021-01468-3.

Acknowledgements The authors gratefully acknowledge financial support from the Research Council of Norway (RCN) via the FRIPRO program (grant number 262370) and via the Norwegian NMR Platform, NNP (226244). The RCN is also thanked for CPU (NN2506K) and storage resources (NS2506K). Bjarte Holmelid is thanked for assistance with the HRMS ESI ${ }^{+}$analyses and Inger Johanne Fjellanger for assistance with the elemental analysis.

Funding Open access funding provided by University of Bergen (incl Haukeland University Hospital). The authors gratefully acknowledge financial support from the Research Council of Norway (RCN) via the FRIPRO program (grant number 262370) and via the Norwegian NMR Platform, NNP (226244). The RCN is also thanked for CPU $(\mathrm{NN} 2506 \mathrm{~K})$ and storage resources (NS2506K.

Availability of data and material The crystal structure of compound Ru21c is available in the Cambridge Structural Database (CSD, as compound number CCDC- 2,086,885). The following is available in an additional supporting file (PDF): A description of the experimental procedures and of additional experimental results, NMR, MS, and $\mathrm{X}$-ray data for new compounds, a description of the computational details and of additional computational results, and calculated electronic and free energies of all computationally investigated minima and transition states. The corresponding DFT-optimized molecular Cartesian coordinates are available in an additional supporting file, in a format convenient for visualization (XYZ).
Conflict of interest The authors declare no competing financial interest.

Open Access This article is licensed under a Creative Commons Attribution 4.0 International License, which permits use, sharing, adaptation, distribution and reproduction in any medium or format, as long as you give appropriate credit to the original author(s) and the source, provide a link to the Creative Commons licence, and indicate if changes were made. The images or other third party material in this article are included in the article's Creative Commons licence, unless indicated otherwise in a credit line to the material. If material is not included in the article's Creative Commons licence and your intended use is not permitted by statutory regulation or exceeds the permitted use, you will need to obtain permission directly from the copyright holder. To view a copy of this licence, visit http://creativecommons.org/licenses/by/4.0/.

\section{References}

1. Kukla DL, Canchola J, Mills JJ (2020) Synthesis of the cyanobacterial antibiotics anaephenes A and B. J Nat Prod 83:2036-2040. https://doi.org/10.1021/acs.jnatprod.0c00279

2. Martin-Galvez F, Garcia-Ruiz C, Sanchez-Ruiz A, Valeriote FA, Sarabia F (2013) An array of bengamide E analogues modified at the terminal olefinic position: synthesis and antitumor properties. ChemMedChem 8:819-831. https://doi.org/10.1002/cmdc. 201300033

3. Teranishi T, Kuwahara S (2014) Stereoselective approach to the DEF ring system of terpendole E. Tetrahedron Lett 55:14861487. https://doi.org/10.1016/j.tetlet.2014.01.050

4. Schulz MD, Wagener KB (2014) Precision polymers through ADMET polymerization. Macromol Chem Phys 215:19361945. https://doi.org/10.1002/macp.201400268

5. Wittig G, Schöllkopf U (1954) Über Triphenyl-phosphin-methylene als olefinbildende Reagenzien (I. Mitteil Chemische Berichte 87:1318-1330. https://doi.org/10.1002/cber.19540870919

6. Wadsworth WS, Emmons WD (1961) The utility of phosphonate carbanions in olefin synthesis. J Am Chem Soc 83:1733-1738. https://doi.org/10.1021/ja01468a042

7. Julia M, Paris J-M (1973) Syntheses a l'aide de sulfones v(+)methode de synthese generale de doubles liaisons. Tetrahedron Lett 14:4833-4836. https://doi.org/10.1016/s0040-4039(01) $87348-2$

8. Hoveyda AH, Zhugralin AR (2007) The remarkable metal-catalysed olefin metathesis reaction. Nature 450:243-251. https:// doi.org/10.1038/nature06351

9. Grela K (2014) Olefin metathesis: Theory and practice. John Wiley \& Sons Inc: Hoboken. https://doi.org/10.1002/97811 18711613

10. Grubbs RH, Wenzel AG, O'Leary DJ, Khosravi E (2015) Handbook of Metathesis. Wiley-VCH, Weinheim. https://doi.org/10. 1002/9783527674107

11. Trnka TM, Grubbs RH (2001) The development of $\mathrm{L} 2 \mathrm{X} 2 \mathrm{Ru}=\mathrm{CHR}$ olefin metathesis catalysts: an organometallic success story. Acc Chem Res 34:18-29. https://doi.org/10.1021/ $\operatorname{ar} 000114 \mathrm{f}$

12. Piola L, Nahra F, Nolan SP (2015) Olefin metathesis in air. Beilstein J Org Chem 11:2038-2056. https://doi.org/10.3762/bjoc.11. 221

\section{Declaration}


13. Kajetanowicz A, Chwalba M, Gawin A, Tracz A, Grela K (2019) Non-glovebox ethenolysis of ethyl oleate and FAME at larger scale utilizing a cyclic (Alkyl)(Amino)Carbene Ruthenium catalyst. Eur J Lipid Sci Technol. https://doi.org/10.1002/ejlt.20190 0263

14. Walensky LD, Bird GH (2014) Hydrocarbon-stapled peptides: principles, practice, and progress. J Med Chem 57:6275-6288. https://doi.org/10.1021/jm4011675

15. Vinogradova EV (2017) Organometallic chemical biology: an organometallic approach to bioconjugation. Pure Appl Chem 89:1619-1640. https://doi.org/10.1515/pac-2017-0207

16. Isenegger PG, Davis BG (2019) Concepts of catalysis in siteselective protein modifications. J Am Chem Soc 141:8005-8013. https://doi.org/10.1021/jacs.8b13187

17. Messina MS, Maynard HD (2020) Modification of proteins using olefin metathesis. Materials Chemistry Frontiers 4:1040-1051. https://doi.org/10.1039/c9qm00494g

18. Higman CS, Lummiss JA, Fogg DE (2016) Olefin metathesis at the dawn of implementation in pharmaceutical and specialtychemicals manufacturing. Angew Chem Int Ed Engl 55:35523565. https://doi.org/10.1002/anie.201506846

19. Yu M, Lou S, Gonzalez-Bobes F (2018) Ring-closing metathesis in pharmaceutical development: fundamentals, applications, and future directions. Org Process Res Dev 22:918-946. https://doi. org/10.1021/acs.oprd.8b00093

20. Cink RD, Lukin KA, Bishop RD, Zhao G, Pelc MJ, Towne TB, Gates BD, Ravn MM, Hill DR, Ding C, Cullen SC, Mei J, Leanna MR, Henle J, Napolitano JG, Nere NK, Chen S, Sheikh A, Kallemeyn JM (2019) Development of the enabling route for glecaprevir via ring-closing metathesis. Org Process Res Dev 24:183-200. https://doi.org/10.1021/acs.oprd.9b00469

21. St-Pierre G, Cherney AH, Chen W, Dong X, Dornan PK, Griffin DJ, Houk KN, Lin JB, Osgood S, Silva Elipe MV, Timmons HC, Xie Y, Tedrow JS, Thiel OR, Smith AG (2020) Accelerated development of a scalable ring-closing metathesis to manufacture AMG 176 using a combined high-throughput experimentation and computational modeling approach. Org Process Res Dev 25:442-451. https://doi.org/10.1021/acs.oprd.0c00416

22. Choi TL, Grubbs RH (2003) Controlled living ring-openingmetathesis polymerization by a fast-initiating ruthenium catalyst. Angew Chem Int Ed Engl 42:1743-1746. https://doi.org/10.1002/ anie. 200250632

23. Schrock RR (2011) Synthesis of stereoregular ROMP polymers using molybdenum and tungsten imido alkylidene initiators. Dalton Trans 40:7484-7495. https://doi.org/10.1039/c1dt10215j

24. Dong Y, Matson JB, Edgar KJ (2017) Olefin cross-metathesis in polymer and polysaccharide chemistry: a review. Biomacromol 18:1661-1676. https://doi.org/10.1021/acs.biomac.7b00364

25. Edwards JP, Wolf WJ, Grubbs RH (2018) The synthesis of cyclic polymers by olefin metathesis: Achievements and challenges. J Polym Sci, Part A: Polym Chem 57:228-242. https://doi.org/10. 1002/pola.29253

26. Debsharma T, Behrendt FN, Laschewsky A, Schlaad H (2019) Ring-opening metathesis polymerization of biomass-derived levoglucosenol. Angew Chem Int Ed Engl 58:6718-6721. https://doi. org/10.1002/anie.201814501

27. Jung K, Ahmed TS, Lee J, Sung JC, Keum H, Grubbs RH, Choi TL (2019) Living beta-selective cyclopolymerization using Ru dithiolate catalysts. Chem Sci 10:8955-8963. https://doi.org/10. 1039/c9sc01326a

28. Feist JD, Xia Y (2020) Enol ethers are effective monomers for ring-opening metathesis polymerization: synthesis of degradable and depolymerizable Poly(2,3-dihydrofuran). J Am Chem Soc 142:1186-1189. https://doi.org/10.1021/jacs.9b11834

29. Foster JC, Grocott MC, Arkinstall LA, Varlas S, Redding MJ, Grayson SM, O'Reilly RK (2020) It is better with salt: aqueous ring-opening metathesis polymerization at neutral $\mathrm{pH}$. J Am Chem Soc 142:13878-13885. https://doi.org/10.1021/jacs.0c054 99

30. Rizzo A, Peterson GI, Bhaumik A, Kang C, Choi TL (2021) Sugar-based polymers from d-Xylose: Living cascade polymerization, tunable degradation, and small molecule release. Angew Chem Int Ed Engl 60:849-855. https://doi.org/10.1002/anie. 202012544

31. Debsharma T, Schmidt B, Laschewsky A, Schlaad H (2021) Ring-opening metathesis polymerization of unsaturated carbohydrate derivatives: levoglucosenyl alkyl ethers. Macromolecules 54:2720-2728. https://doi.org/10.1021/acs.macromol.0c02821

32. Vougioukalakis GC, Grubbs RH (2010) Ruthenium-based heterocyclic carbene-coordinated olefin metathesis catalysts. Chem Rev 110:1746-1787. https://doi.org/10.1021/cr9002424

33. Montgomery TP, Johns AM, Grubbs RH (2017) Recent advancements in stereoselective olefin metathesis using ruthenium catalysts. Catalysts. https://doi.org/10.3390/catal7030087

34. Ogba OM, Warner NC, O’Leary DJ, Grubbs RH (2018) Recent advances in ruthenium-based olefin metathesis. Chem Soc Rev 47:4510-4544. https://doi.org/10.1039/c8cs00027a

35. Fürstner A (2013) Teaching metathesis "simple" stereochemistry. Science 341:1229713. https://doi.org/10.1126/science.1229713

36. Muller DS, Basle O, Mauduit M (2018) A tutorial review of stereoretentive olefin metathesis based on ruthenium dithiolate catalysts. Beilstein J Org Chem 14:2999-3010. https://doi.org/ 10.3762/bjoc. 14.279

37. Dawood KM, Nomura K (2021) Recent developments in Z-selective olefin metathesis reactions by molybdenum, tungsten, ruthenium, and vanadium Catalysts. Adv Synth Catal 363:1970-1997. https://doi.org/10.1002/adsc.202001117

38. Endo K, Grubbs RH (2011) Chelated ruthenium catalysts for Z-selective olefin metathesis. J Am Chem Soc 133:8525-8527. https://doi.org/10.1021/ja202818v

39. Dang Y, Wang Z-X, Wang X (2012) Does the ruthenium nitrato catalyst work differently in Z-selective olefin metathesis? A DFT study. Organometallics 31:8654-8657. https://doi.org/10. 1021/om300972h

40. Dang Y, Wang Z-X, Wang X (2012) A thorough DFT study of the mechanism of homodimerization of terminal olefins through metathesis with a chelated ruthenium catalyst: from initiation to $\mathrm{Z}$ selectivity to regeneration. Organometallics 31:7222-7234. https://doi.org/10.1021/om300784k

41. Bronner SM, Herbert MB, Patel PR, Marx VM, Grubbs RH (2014) Ru-based Z-selective metathesis catalysts with modified cyclometalated carbene ligands. Chem Sci 5:4091-4098. https:// doi.org/10.1039/C4SC01541J

42. Herbert MB, Suslick BA, Liu P, Zou L, Dornan PK, Houk KN, Grubbs RH (2015) Cyclometalated Z-selective ruthenium metathesis catalysts with modified $\mathrm{N}$-chelating groups. Organometallics 34:2858-2869. https://doi.org/10.1021/acs.organomet. 5 b00185

43. Dumas A, Tarrieu R, Vives T, Roisnel T, Dorcet V, Baslé O, Mauduit M (2018) A versatile and highly Z-selective olefin metathesis ruthenium catalyst based on a readily accessible N-Heterocyclic Carbene. ACS Catal 8:3257-3262. https://doi.org/10.1021/acsca tal.8b00151

44. Xu Y, Wong JJ, Samkian AE, Ko JH, Chen S, Houk KN, Grubbs RH (2020) Efficient Z-selective Olefin-Acrylamide cross-metathesis enabled by sterically demanding cyclometalated ruthenium catalysts. J Am Chem Soc 142:20987-20993. https://doi.org/10. 1021/jacs.0c11334

45. Occhipinti G, Hansen FR, Törnroos KW, Jensen VR (2013) Simple and highly Z-selective ruthenium-based olefin metathesis catalyst. J Am Chem Soc 135:3331-3334. https://doi.org/10.1021/ ja311505v 
46. Occhipinti G, Koudriavtsev V, Törnroos KW, Jensen VR (2014) Theory-assisted development of a robust and Z-selective olefin metathesis catalyst. Dalton Trans 43:11106-11117. https://doi. org/10.1039/c4dt00409d

47. Nelson JW, Grundy LM, Dang Y, Wang Z-X, Wang X (2014) Mechanism of $Z$-selective olefin metathesis catalyzed by a ruthenium monothiolate carbene complex: A DFT study. Organometallics 33:4290-4294. https://doi.org/10.1021/om500612r

48. Smit W, Koudriavtsev V, Occhipinti G, Törnroos KW, Jensen VR (2016) Phosphine-Based Z-Selective Ruthenium Olefin Metathesis Catalysts. Organometallics 35:1825-1837. https://doi.org/10. 1021/acs.organomet.6b00214

49. Occhipinti G, Törnroos KW, Jensen VR (2017) Pyridine-stabilized fast-initiating ruthenium monothiolate catalysts for Z-selective olefin metathesis. Organometallics 36:3284-3292. https://doi. org/10.1021/acs.organomet.7b00441

50. Smit W, Ekeli JB, Occhipinti G, Woźniak B, Törnroos KW, Jensen VR (2020) Z-selective monothiolate ruthenium indenylidene olefin metathesis catalysts. Organometallics 39:397-407. https://doi. org/10.1021/acs.organomet.9b00641

51. Renom-Carrasco M, Mania P, Sayah R, Veyre L, Occhipinti G, Jensen VR, Thieuleux C (2020) Silica-supported Z-selective Ru olefin metathesis catalysts. Molecular Catalysis. https://doi.org/ 10.1016/j.mcat.2019.110743

52. Khan RK, Torker S, Hoveyda AH (2014) Reactivity and selectivity differences between catecholate and catechothiolate Ru complexes. Implications regarding design of stereoselective olefin metathesis catalysts. J Am Chem Soc 136:14337-14340. https:// doi.org/10.1021/ja505961z

53. Koh MJ, Khan RK, Torker S, Yu M, Mikus MS, Hoveyda AH (2015) High-value alcohols and higher-oxidation-state compounds by catalytic Z-selective cross-metathesis. Nature 517:181-186. https://doi.org/10.1038/nature14061

54. Xu C, Shen X, Hoveyda AH (2017) In situ methylene capping: a general strategy for efficient stereoretentive catalytic olefin metathesis. The concept, methodological implications, and applications to synthesis of biologically active compounds. J Am Chem Soc 139:10919-10928. https://doi.org/10.1021/jacs.7b06552

55. Liu Z, Xu C, Del Pozo J, Torker S, Hoveyda AH (2019) Ru-based catechothiolate complexes bearing an unsaturated nhe ligand: effective cross-metathesis catalysts for synthesis of (Z)-alpha, beta-unsaturated esters, carboxylic acids, and primary, secondary, and weinreb amides. J Am Chem Soc 141:7137-7146. https:// doi.org/10.1021/jacs.9b02318

56. Montgomery TP, Grandner JM, Houk KN, Grubbs RH (2017) Synthesis and evaluation of sterically demanding ruthenium dithiolate catalysts for stereoretentive olefin metathesis. Organometallics 36:3940-3953. https://doi.org/10.1021/acs.organomet.7b005 55

57. Jean-Louis Hérisson P, Chauvin Y (1971) Catalyse de transformation des oléfines par les complexes du tungsténe. Die Makromolekulare Chemie 141:161-176. https://doi.org/10.1002/macp.1971. 021410112

58. Miyazaki H, Herbert MB, Liu P, Dong X, Xu X, Keitz BK, Ung T, Mkrtumyan G, Houk KN, Grubbs RH (2013) Z-Selective ethenolysis with a ruthenium metathesis catalyst: experiment and theory. J Am Chem Soc 135:5848-5858. https://doi.org/10.1021/ja401 0267

59. Minenkov Y, Occhipinti G, Jensen VR (2013) Complete reaction pathway of ruthenium-catalyzed olefin metathesis of ethyl vinyl ether: kinetics and mechanistic insight from DFT. Organometallics 32:2099-2111. https://doi.org/10.1021/om301192a

60. Grandner JM, Shao H, Grubbs RH, Liu P, Houk KN (2017) Origins of the stereoretentive mechanism of olefin metathesis with ru-dithiolate catalysts. J Org Chem 82:10595-10600. https://doi. org/10.1021/acs.joc.7b02129
61. Vyboishchikov SF, Bühl M, Thiel W (2002) Mechanism of olefin metathesis with catalysis by ruthenium carbene complexes: density functional studies on model systems. Chem Eur J 8:3962-3975

62. Khan RK, Torker S, Hoveyda AH (2013) Readily accessible and easily modifiable Ru-based catalysts for efficient and Z-selective ring-opening metathesis polymerization and ring-opening/crossmetathesis. J Am Chem Soc 135:10258-10261. https://doi.org/ 10.1021/ja404208a

63. Johns AM, Ahmed TS, Jackson BW, Grubbs RH, Pederson RL (2016) High trans kinetic selectivity in ruthenium-based olefin cross-metathesis through stereoretention. Org Lett 18:772-775. https://doi.org/10.1021/acs.orglett.6b00031

64. Mikus MS, Torker S, Xu C, Li B, Hoveyda AH (2016) Pentacoordinate ruthenium(II) catecholthiolate and mercaptophenolate catalysts for olefin metathesis: anionic ligand exchange and ease of initiation. Organometallics 35:3878-3892. https://doi.org/10. 1021/acs.organomet.6b00773

65. Testaferri L, Tingoli M, Tiecco M (1980) A convenient synthesis of aromatic thiols from unactivated aryl halides. Tetrahedron Lett 21:3099-3100. https://doi.org/10.1016/s0040-4039(00)77418-1

66. Drouin SD, Foucault HM, Yap GPA, Fogg DE (2005) New pseudohalide ligands in Ru-catalyzed olefin metathesis - A robust, air-activated iminopyrrolato catalyst. Can J Chem 83:748-754. https://doi.org/10.1139/v05-039

67. Neumann B, Krinninger C, Lorenz I-P (2007) Synthesis, Structures and Comparison of Neutral Complexes Formed by2-(2'Pyridyl)indole and d6 Transition Metals. Eur J Inorg Chem 2007:472-480. https://doi.org/10.1002/ejic.200600730

68. Ueno A, Kayaki Y, Ikariya T (2014) Heterolysis of NH-Indoles by bifunctional amido complexes and applications to carboxylation with carbon dioxide. Organometallics 33:4479-4485. https://doi. org/10.1021/om500695a

69. Higman CS, Lanterna AE, Marin ML, Scaiano JC, Fogg DE (2016) Catalyst decomposition during olefin metathesis yields isomerization-active ruthenium Nanoparticles. ChemCatChem 8:2446-2449. https://doi.org/10.1002/cctc.201600738

70. Higman CS, Plais L, Fogg DE (2013) Isomerization during olefin metathesis: an assessment of potential catalyst culprits. ChemCatChem 5:3548-3551. https://doi.org/10.1002/cctc.201300886

71. Bailey GA, Lummiss JAM, Foscato M, Occhipinti G, McDonald R, Jensen VR, Fogg DE (2017) Decomposition of olefin metathesis catalysts by bronsted base: metallacyclobutane deprotonation as a primary deactivating event. J Am Chem Soc 139:1644616449. https://doi.org/10.1021/jacs.7b08578

72. Bailey GA, Foscato M, Higman CS, Day CS, Jensen VR, Fogg DE (2018) Bimolecular coupling as a vector for decomposition of fast-initiating olefin metathesis catalysts. J Am Chem Soc 140:6931-6944. https://doi.org/10.1021/jacs.8b02709

73. Bahri-Laleh N, Credendino R, Cavallo L (2011) The intriguing modeling of cis-trans selectivity in ruthenium-catalyzed olefin metathesis. Beilstein J Org Chem 7:40-45. https://doi.org/10. 3762/bjoc.7.7

74. Janse van Rensburg W, Steynberg PJ, Meyer WH, Kirk MM, Forman GS (2004) DFT prediction and experimental observation of substrate-induced catalyst decomposition in ruthenium-catalyzed olefin metathesis. J Am Chem Soc 126:14332-14333. https://doi. org $/ 10.1021 / \mathrm{ja} 0453174$

75. Lummiss JAM, Botti AGG, Fogg DE (2014) Isotopic probes for ruthenium-catalyzed olefin metathesis. Catal Sci Technol 4:4210 4218. https://doi.org/10.1039/c4cy01118j

76. Ireland BJ, Dobigny BT, Fogg DE (2015) Decomposition of a phosphine-free metathesis catalyst by amines and other bronsted bases: metallacyclobutane deprotonation as a major deactivation pathway. ACS Catal 5:4690-4698. https://doi.org/10.1021/acsca tal.5b00813 
77. Montgomery TP, Ahmed TS, Grubbs RH (2017) Stereoretentive Olefin Metathesis: An Avenue to Kinetic Selectivity. Angew Chem Int Ed Engl 56:11024-11036. https://doi.org/10.1002/anie. 201704686
Publisher's Note Springer Nature remains neutral with regard to jurisdictional claims in published maps and institutional affiliations.

\section{Authors and Affiliations}

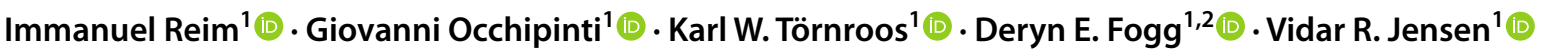

$\triangle$ Vidar R. Jensen

Vidar.Jensen@uib.no

1 Department of Chemistry, University of Bergen, Allégaten 41, N-5007 Bergen, Norway
2 Center for Catalysis Research \& Innovation, and Department of Chemistry and Biomolecular Sciences, University of Ottawa, Ottawa, ON K1N 6N5, Canada 